\title{
DESIGN OF A 4X4 SQUARE MICROSTRIP PLANAR ARRAY
}

\author{
Anitha.V.R ${ }^{1}$, Dr. S. Narayana Reddy ${ }^{2}$, Mohamed Ismaeel ${ }^{3}$ \\ ${ }^{1,2}$ Dept of EEE, SV University, Tirupati, \\ ${ }^{3}$ Sathyabama University,Chennai, E-Mail:'anithavr@yahoo.com, ${ }^{1}$ snreddysvu@yahoo.com, ${ }^{3}$ pslu@narl.gov.in
}

\begin{abstract}
Wind profiling radars operating in Doppler beam swinging mode needs to have large antenna array in order to have a narrow beam for wind direction accuracy. To meet the above requirement, in the present work an array with 16 elements configured in a $4 X 4$ square matrix is designed. The antenna inserted is a coaxial probe (Probe Feed) to the patch near its resonance in ' $L$ ' band is carried out. Principal plane 2-dimensional radiation patterns at $1.28 \mathrm{GHz}$ have been computed for single element and $4 \mathrm{X} 4$ planar arrays. The results of linearly polarized coaxial probe single element are generated by using IE3D software. Using this single element as basic building block, $\mathrm{a} 2 \mathrm{X} 2$ and $4 \mathrm{X} 4$ planar arrays was designed. The results obtained are presented succinctly. The inferences from the design of coaxial probe antenna are presented. The Impedance Band-Width, 3-dB Beam Width and Gain for a single element as well as a 4 X 4 planar array are compared.
\end{abstract}

Key words: : Microstrip Patch Antenna, MST Radar, Wind Profiling Radar, Coaxial Feed, IE3D Software.

\section{INTRODUCTION}

Microstrip patch antennas (MPAs) have attracted widespread interest due, for example, to their small size, light weight, low profile and low cost as well as to the fact that they are simple to manufacture, suited to planar and nonplanar surfaces, mechanically robust, easily integrated with circuits, allow multifrequency operation to be achieved and so forth [1]. However, their further use in specific systems is limited because of their relatively narrow bandwidth. In principal, wide bandwidth of microstrip patch antennas (MPAs) or bandwidth enhancement can be achieved by several efficient approaches [2], namely (i) increasing the substrate thickness (ii) optimizing impedance matching (iii) reducing the substrate effective permittivity or (iv) incorporating multiple resonance. Much effort has also been increasingly devoted to increasing the frequency agility of (MPAs) [2].

At the same time, MPAs need to be extremely small and compact to satisfy the severe size constraints of some critical applications such as mobile cellular handsets, cordless phones and Bluetooth devices. The miniaturization of normal MPA size [1] has typically been accomplished by loading, which can take various forms, such as (i) using a high permittivity substrate, (ii) using shorting posts or shorting pins, or (iii) modifying the basic patch shape [3].

In this paper, coaxial feed [3], [4], [5] techniques are applied to the square microstrip patch antenna. Because, Coaxial feed is a widely used one. The inner conductor of coax is connected to the radiating patch and the outer conductor is connected to the ground plane. This feed is also easy to match, and it has low spurious radiation. However, it has a narrow bandwidth and is difficult to model, especially for very thick substrates. The advantage of this feed is that it occupies less space than the microstrip feed.

\section{ANTENNA DESIGN}

Design procedures, for a single element, a 2X2 array, and a $4 X 4$ array are outlined, to meet the specified performance characteristics.

\section{A. Specifications for Wind Profiling Radars}

Either the single element or the $4 \mathrm{X} 4$ array is to be designed for the same set of specifications. These specifications are

$\begin{array}{ll}\text { Frequency of operation } & : 1.28 \mathrm{GHz} \\ \text { Polarization } & : \text { Linear } \\ \text { Bandwidth } & : 20 \mathrm{MHZ} \\ \text { Beam Width } & : 4.3^{\circ}-5^{\circ} \\ \text { Feed } & : \text { Co-axial } \\ \text { Configuration } & : \text { Square } \\ \text { Gain } & : 32 \mathrm{dBi} \\ \text { Antenna Element } & : \text { MPA } \\ \text { No of Elements } & : 256 \\ \text { Inter Element Spacing } & : 0.73 \lambda \\ \text { Size of the array } & : 2.74 \mathrm{~m} \\ \text { Grid } & : \text { Square } \\ \text { Beam Switching Speed } & : \text { Pulse-to- } \\ & \text { pulse }\end{array}$

As per the specifications, the specified gain and beam width for the microstrip antenna cannot be achieved by using a single radiating element and there is a need for going to a large antenna array configuration. The required beam widths and gain can be obtained by using a planar array structure. In that way I have been designed $4 X 4$ microstrip planar array.

\section{B. Design of Single Element}

Design involves the determination of the length of the patch from the knowledge of the resonant frequency $f_{r}$ (in $\mathrm{Hz}$ ), thickness of the substrate $\mathrm{h}$ (in $\mathrm{mm}$ ), and the dielectric 
constant $\varepsilon_{\mathrm{r}}$. Optimization of the parameters of the single element is performed using IE3D simulation software [7]. The layout for a single element is obtained using IE3D software [7]. The layout is shown in Fig 1.

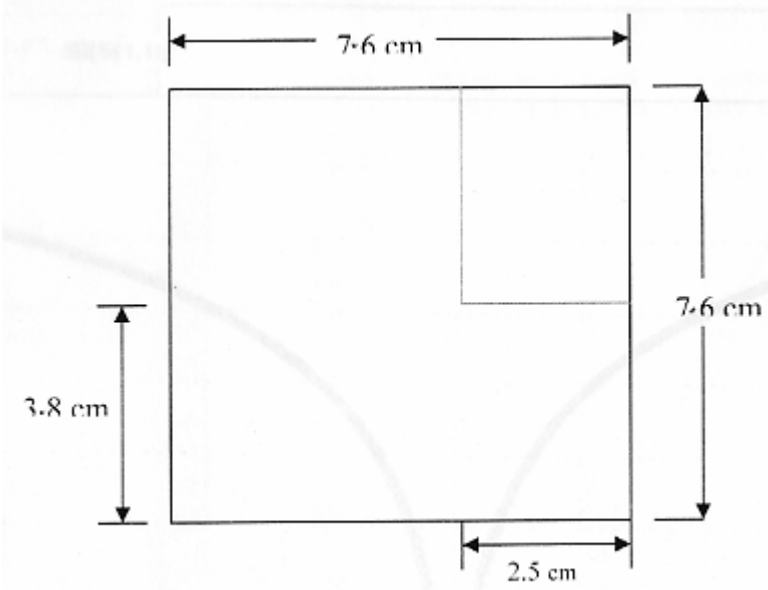

Fig.1. Single Element Square Microstrip Antenna.

\section{CDesign of a 22 PlanarArray}

The finalized single element is used for the design of $2 \times 2$ planar array. The schematic of the array is shown in the Fig 2.

Fig 2 shows the four-element sub array forms the basic building block for the entire array. The four elements are designed in a $2 \times 2$ square grid configuration with element spacing $0.73 \lambda_{0}\left(\lambda_{0}\right.$ is the free space wavelength).

Theoretical values of gain and Beam width of the 2X2 planar array are calculated. The calculated Beam width and gain values for $2 X 2$ planar array are $35^{\circ}$ and $14.3 \mathrm{~dB}$.
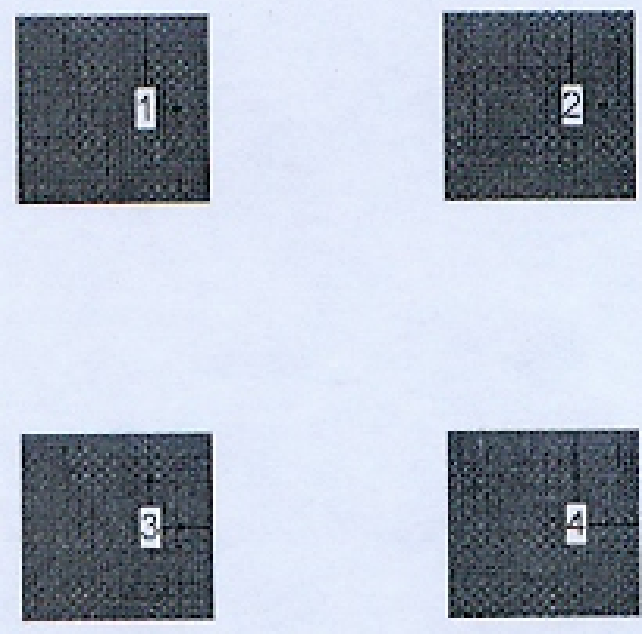

Fig.2 2X2 Microstrip Planar Array

\section{DDesign of 44 PlanarArray}

To achieve the required gain $20.3 \mathrm{~dB}$, a $4 \mathrm{X} 4$ planar array is shown in Fig 3 . has been designed using the $2 X 2$ planar array as the basic building block. In the $4 X 4$ microstrip planar array each $2 X 2$ array, which is used as a basic building block, is oriented in a sequential manner as employed in the $2 X 2$ array. Theoretical values of gain and beam width for $4 \mathrm{X} 4$ planar array are $20.3 \mathrm{~dB}$ and $17.5^{\circ}$.

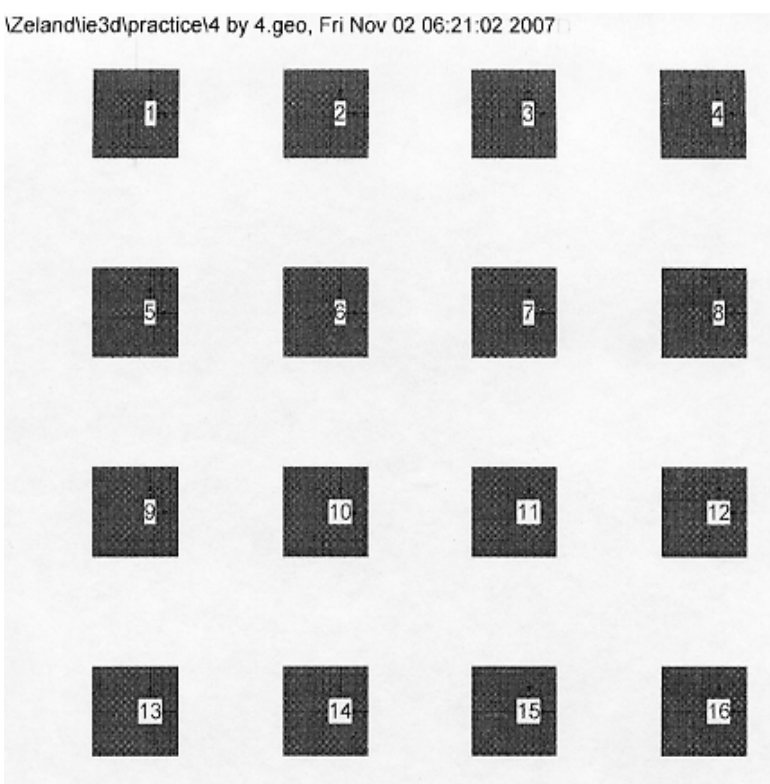

Fig.3. Schematic Diagram of a 4X4 Array

\section{RESULTS AND DISCUSSIONS}

In this paper the simulation results obtained for coaxial feed microstrip antennas viz., single element, 4X4 planar array are presented. The results for the optimized single element with coaxial feed are shown in section 4.1. Using this antenna as radiating element a $2 \times 2$ array was designed. A 4X4 array was designed by using $2 \times 2$ element array as basic building block. The realization of single element, 2X2 planar array and 4X4 planar array is carried out on a dielectric substrate of 125 mil $(3.175 \mathrm{~mm})$ thick with dielectric constant of 2.2 (RT/Duroid).

\section{A. Results of Single Element Microstrip Antenna}

The measured return loss of the single element microstrip antenna is shown in Fig 4. While measuring impedance bandwidth $10 \mathrm{~dB}$ return loss is considered. The measured radiation patterns, Gain and Directivity plots are shown in Fig 5-7. 


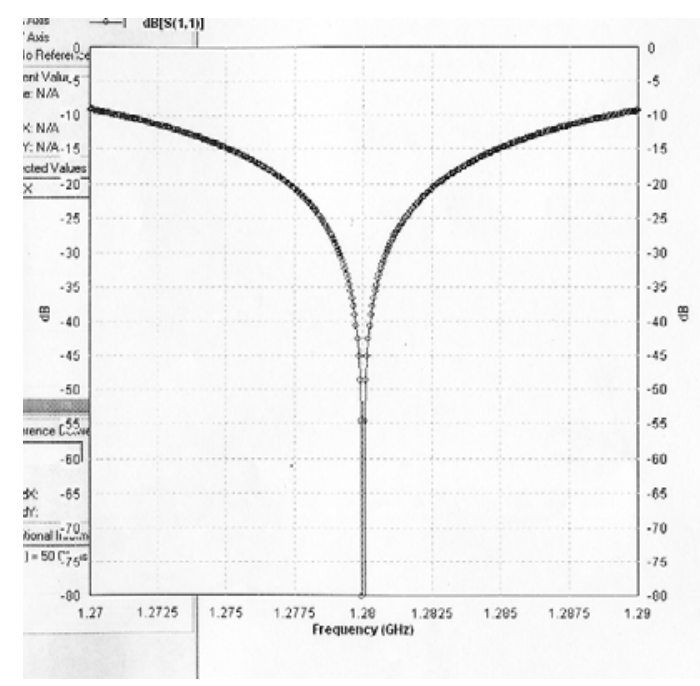

Fig.4. Return Loss Plot of Single Element

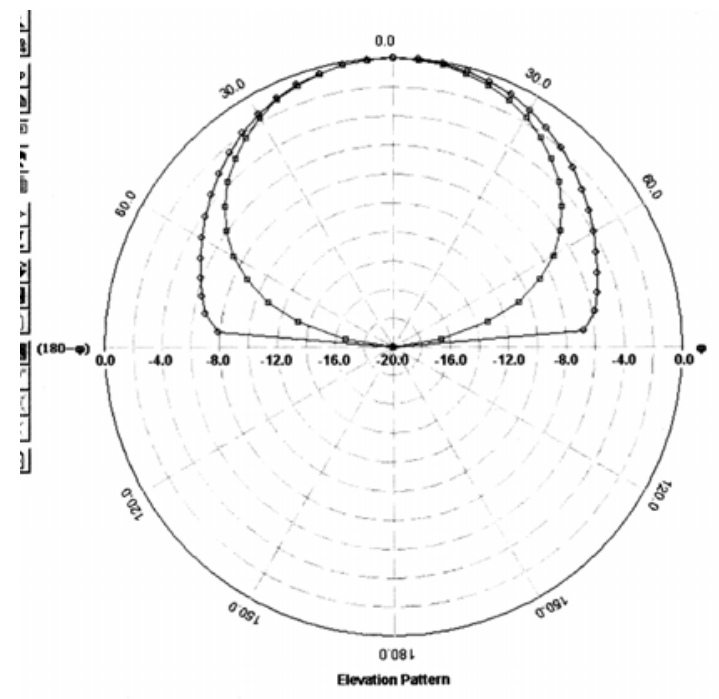

Fig.5. Radiation Pattern at $1.28 \mathrm{GHz}$

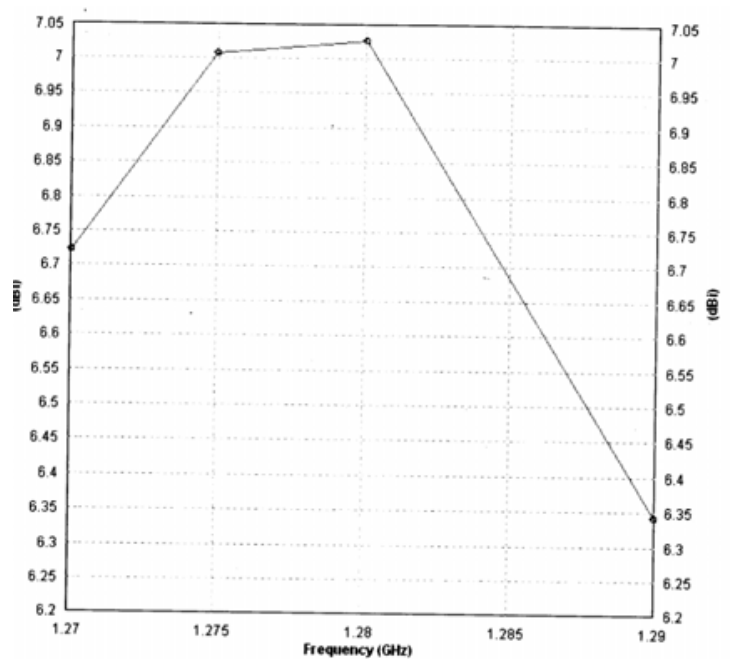

Fig.6. Gain of Single Element with varying Frequency

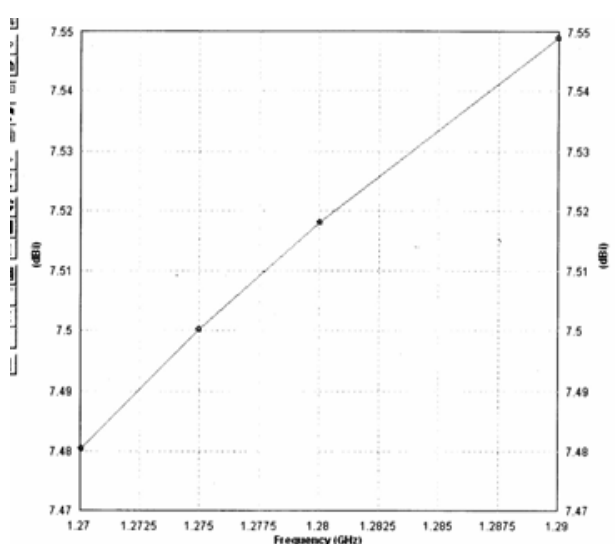

Fig.7. Directivity vs Frequency

\section{B. Results of 4X4 Microstrip Planar Array}

The measured return loss of the $4 X 4$ planar array using coaxial feed microstrip antenna is shown in Fig 8. The measured radiation patterns, Gain and Directivity at frequency 1.28 GHz are shown in Fig 9-14.

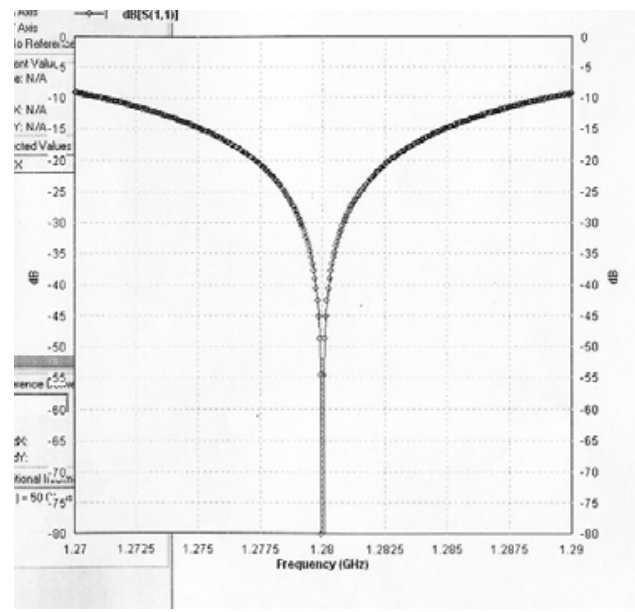

Fig.8. Return Loss Plot of a 4X4 Array

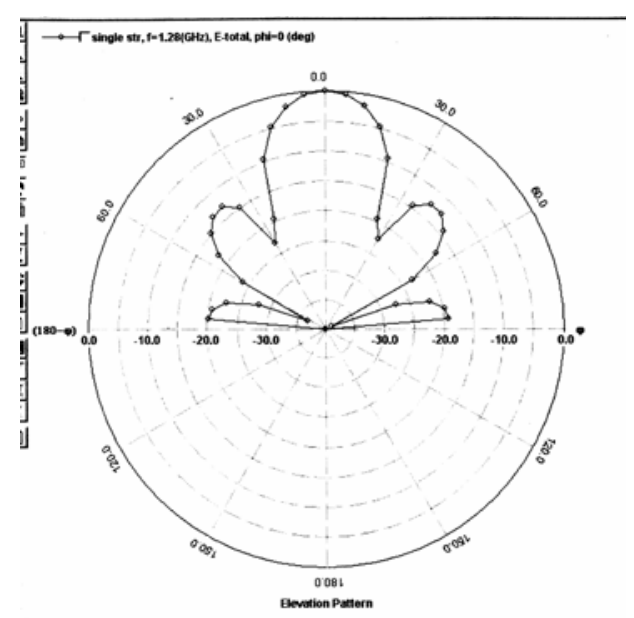

Fig.9. Radiation Pattern at $\Phi=0$ of the $4 X 4$ Microstrip Planar Array 


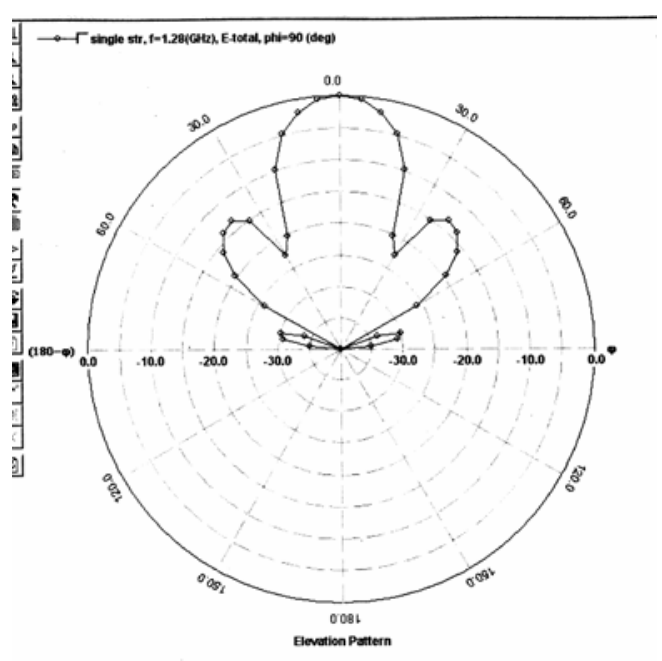

Fig.10. Radiation Pattern at $\Phi=90$ of the $4 X 4$ Microstrip Planar Array

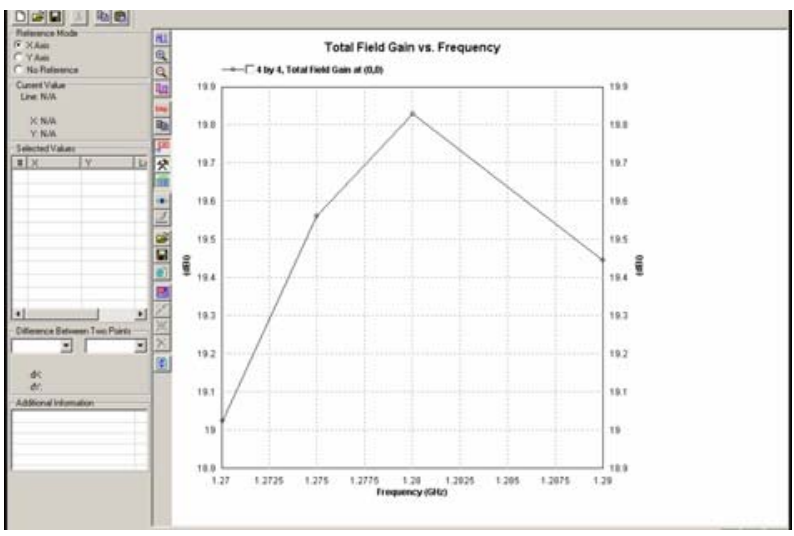

Fig.11. Gain of 4 X4 Planar Array with varying Frequency

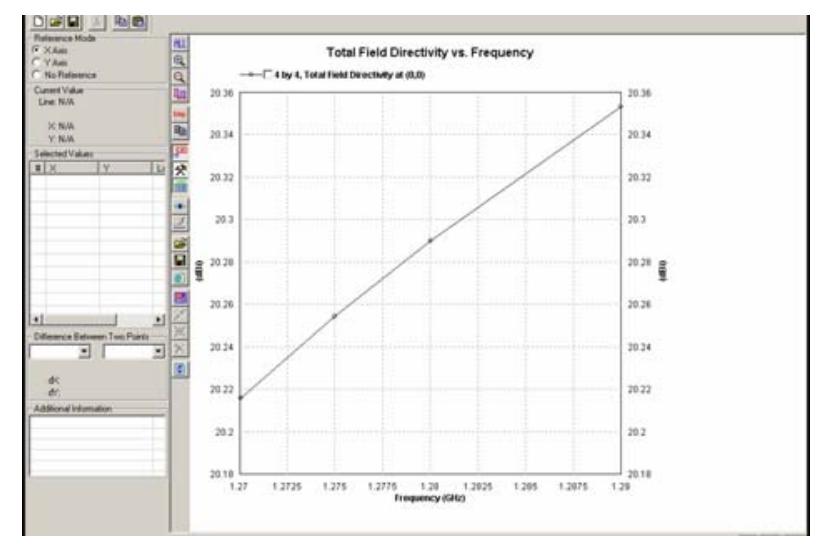

Fig.12. Directivity of a 4X4 Planar Array

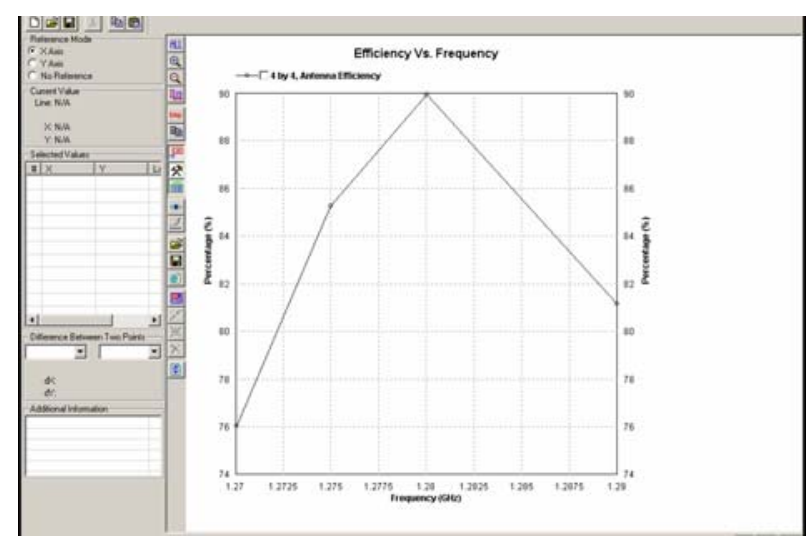

Fig.14. Antenna Efficiency Varying with Frequency

\section{CONCLUSIONS}

The development and performance of a 4X4 element L-band linear polarization microstrip patch antenna array is described. The design has been carried out by using IE3D simulation software. Using the finalized single element antenna as basic radiating element a microstrip planar array has been successfully developed. The design of $2 X 2$ and $4 X 4$ planar arrays greatly improved the gain and directivity. The design details, typical characteristics and analysis of the proposed antenna have been addressed. The theoretical and simulated results are in good agreement.

\section{REFERENCES}

[1]. JAMES, J.R., and HALL, P.S., 1989 "Handbook of Microstrip Antennas" Peter Peregrinus Ltd., London, UK.

[2]. POZAR, D.M., and SCHAUBERT, D.H., 1995 , "Microstrip Antennas, the Analysis and Design of Microstrip Antennas and Arrays", IEEE Press, New York, USA.

[3]. K.R.CARVER and J.W.MINK, Jan -1981 "Microstrip Antenna Technology", IEEE Trans. Antennas Propag., Vol.AP-29, pp. 2-24.

[4]. I.J.BAHL and P.BHARTIA, 1980.

"Microstrip Antennas", Dedham, MA: Artech House.

[5] J.R.JAMES, P.S.HALL and C.WOOD, 1981 "Microstrip Antenna Theory and Design", London, UK,: Peter Peregrinus,

[6] KUMAR.G and RAY.K.P, 2003 "Broadband Microstrip Antennas", Artech House, Inc.,.

[7] IE3D Software Release 11.0 (Zeland Software Inc., Fremont, California, USA). 
[8] WATERHOUSE, R.B., TARGONSKI, S.D., and KOKOTOFF,D.M., 1998 "Design and Performance of small Printed Antennas", IEEE Trans. Antennas and Propagation, , Vol.46, pp. 1629-1633.

[9] A.K.ROY, A.G.SHARMA, and MANISH KUMAR, "Design of Reduced Size Wide-band Microstrip Antenna for VHF \& Lower UHF Application Using IE3D", B.Tech Project, NERIST, Arunachal Pradesh (India).

[10] K.C.GUPTA and ABDELAZIZ BENALLA, 1988 "Microstrip Antenna Design", Artech House, Inc.

[11] CONSTANTINE A.BALANIS, 2002 "Antenna Theory Analysis and Design", 2 eld, John Wiley \& Sons, Inc.

[12] KAI FONG LEE and WEICHEN, 1997 "Advances in Microstrip and printed Antennas", John Wiley \& Sons, Inc., New York,.

[13] RAMESH GARG, PRAKASH BHARTIA, INDER BHAL, ISAC ITTIPIBOON, , 2001 "Microstrip Antenna Design Hand Book", Artech House.

[14] J.R.JAMES and P.S.HALL, 1989 "Handbook of Microstrip Antennas", Peterpegrinus Ltd., London,.
[15] AS Frisch, B L Weber, R G Strauch, DAMerritt and K P Moran, Dec-1986 "The Altitude coverage of the Colorado Wind Profilers at 50, 405 and 915 MHz", International Oournal of Atmospheric and Oceanic Technology, Vol.3, No.4, pp 680-692.

[16] R R Rogers, W L Ecklund and D A carter, K S Gage and S A Etheir, , April 1993 "research Applications of a Boundary Layer Wind Profile", Bulletin of the American Meteorological Society, Vol.74, No.4, pp 567-580.

[17] P T May and J M Wilczak, March 1993 "Diurnal and Seasonal Variations of Boundary-Layer Structure Observed with a Radar Wind Profiler and RASS", Monthly Weather Review (American Meteorological Society), Vol.121, No.3, pp 673-682.

[18] J B Mead, G Hopcraft, S J Frasier, B D Pollard, C D Cherry, D H Schaubert and R E Mclntosh, August 1998 "A Volume-Imaging Radar Wind Profiler for Atmospheric Boundary Layer Turbulence Studies", International Oournal of Atmospheric and Oceanic technology, Vol.15, pp 849-859,. 